\title{
General Psychiatry A psychological health support scheme for medical teams in COVID-19 outbreak and its effectiveness
}

\author{
Wenhong Cheng (D , ${ }^{1}$ Fang Zhang, ${ }^{2}$ Zhen Liu, ${ }^{3}$ Hao Zhang, ${ }^{2}$ Yifan Lyu, ${ }^{2} \mathrm{Hao} \mathrm{Xu},{ }^{4}$ \\ Yingqi Hua, ${ }^{5}$ Jiarong Gu, ${ }^{6}$ Zhi Yang, ${ }^{7,8}$ Jun Liu ${ }^{9}$
}

To cite: Cheng W, Zhang F, Liu Z, et al. A psychological health support scheme for medical teams in COVID-19 outbreak and its effectiveness. General Psychiatry 2020;33:e100288. doi:10.1136/ gpsych-2020-100288

- Additional material is published online only. To view please visit the journal online (http://dx.doi.org/10.1136/ gpsych-2020-100288).

WC and FZ contributed equally.

Received 31 May 2020

Revised 05 July 2020

Accepted 09 July 2020
A) Check for updates

(c) Author(s) (or their employer(s)) 2020. Re-use permitted under CC BY-NC. No commercial re-use. See rights and permissions. Published by BMJ.

For numbered affiliations see end of article.

Correspondence to Dr Zhi Yang;

yangz@smhc.org.cn

Dr Jun Liu;

liujun-sgh@sjtu.edu.cn

\section{ABSTRACT}

Background Medical staff fighting the COVID-19 pandemic are experiencing stress from high occupational risk, panic in the community and the extreme workload. Maintaining the psychological health of a medical team is essential for efficient functioning, but psychological intervention models for emergency medical teams are rare.

Aims To design a systematic, full-coverage psychological health support scheme for medical teams serving large-scale emergent situations, and demonstrate its effectiveness in a real-world study in Leishenshan Hospital during the COVID-19 epidemic in Wuhan, China.

Methods The scheme integrates onsite and online mental health resources and features team-based psychosocial support and evidence-based interventions. It contained five modules, including a daily measurement of mood, a daily mood broadcast that promotes positive affirmation, a daily online peer-group activity with themes based on the challenges reported by the team, Balint groups and an after-work support team. The daily mood measurement provides information to the other modules. The scheme also respects the special psychological characteristics of medical staff by promoting their strengths.

Results The scheme economically supported a special medical team of 156 members with only one onsite psychiatrist. Our data reflected that the entire medical team maintained an overall positive outlook (7-9 out of 10 in a Daily Mood Index, DMI) for nearly 6 weeks of continuous working. Since the scheme promoted selfstrengths and positive self-affirmation, the number of self-reports of life-related gains were high and played a significant effect on the DMI. Our follow-up investigations also revealed that multiple modules of the scheme received high attention and evaluation levels.

Conclusion Our quantitative data from Leishenshan hospital, Wuhan, China, show that the programme is adequate to support the continuous high workload of medical teams. This scheme could be applied to medical teams dealing with emergent situations.

\section{INTRODUCTION}

To reinforce the shortage of medical services during the outbreak of COVID-19 in Wuhan, China, more than 40000 medical staff from all over the country served in Hubei Province. They worked in hospitals including temporary infectious disease hospitals and in medical isolation units. Due to factors such as the lockdown of Wuhan, prolonged isolation, family infections, lack of medical resources, and witnessing death, these physicians generally experienced stress symptoms or bereavement-related depression. ${ }^{1}$

Faced with patient's infectiousness and psychological needs, as well as locked wards, separation from home, and continuous work, medical staff experienced emotional pain, insomnia, stress reactions and exhaustion. This increased the risk of illness in the staff themselves. ${ }^{2-7}$ In addition, the medical workers became easily dissatisfied with their job. ${ }^{8}$ Due to the emergent nature of the epidemic, many doctors and nurses were not from the departments of infectious diseases, respiratory or intensive care units (ICU), so they lacked confidence in treating COVID-19, which also increased their stress. Therefore, to maintain efficient work, it was essential to alleviate the psychological stress of the team.

There has been a considerable shortage of professional mental health workers in China. $^{9-11}$ In this epidemic, there were only about 250 professional mental health workers among the 40000 medical workers dispatched from outside to Hubei $(0.625 \%)$. In our case, a 156-member medical team from Shanghai General Hospital arrived at Leishenshan Hospital on 19 February and took over 90 beds in two general wards and 32 beds in the ICU. There was only one psychiatrist among the medical team. In addition to maintaining the mental health of medical team members, this psychiatrist also provided psychological support for patients under the jurisdiction of this medical team. Therefore, onsite mental health resources were minimal.

To overcome these difficulties, a psychological health support programme was designed and implemented to reinforce the medical team sent to Leishenshan hospital in Wuhan, 


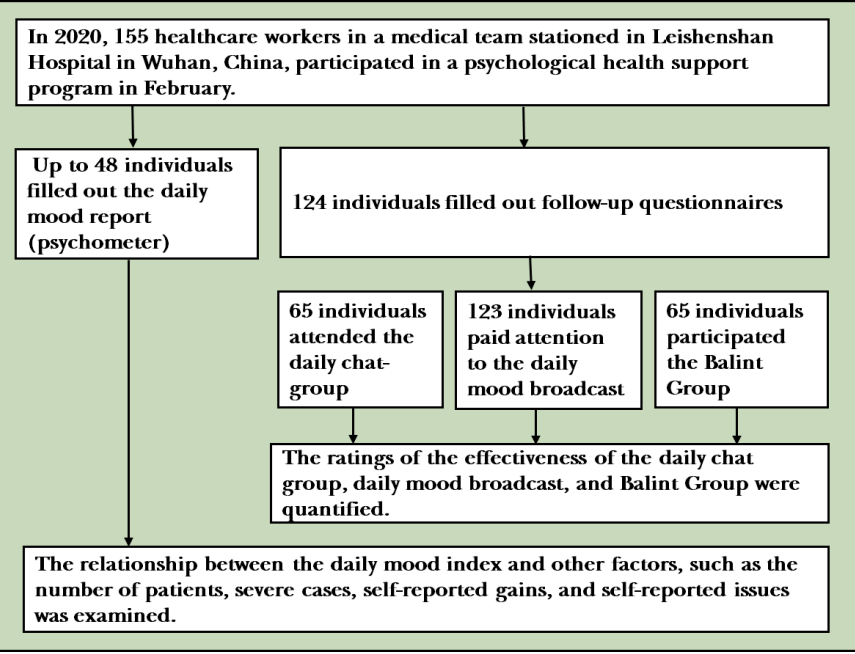

Figure 1 A flowchart for the enrolment and follow-up of participants.

China. The programme was based on strength-oriented peer support groups and positive self-feedback coaching. ${ }^{12}$ Previous studies have demonstrated the effectiveness of peer support group approaches, such as Balint groups, on alleviating the exhaustion of healthcare workers. ${ }^{13-16}$ These activities have been validated both in face-to-face and online forms. ${ }^{17}$

Besides being financially economical and resource efficient, it adapts easily to the special characteristics of healthcare workers. Doctors and nurses tend not to accept the role of help-seeker, and they are more inclined to learn and solve problems by themselves, ${ }^{5} 18$ bringing challenges to classical psychological interventions. Our programme thus emphasised motivating self-strengths by promoting positive self-feedback and coaching selfregulation exercises everyday.

This paper introduces the details of the psychological health support programme and presents data that reflect the effects of this programme. We examined whether this programme can effectively promote positive emotions, maintain team work efficiency and prevent burnout.

\section{METHODS}

\section{Participants}

There were 155 medical personnel in the medical team, including 59 doctors, 90 nurses and 6 administrative staff. Mean age of the team was 35 years (24-54 years), with 49 men $(31.6 \%)$. Figure 1 shows the details of the enrolment and follow-up of subjects in the study.

\section{Psychological intervention}

Figure 2 presents the architecture of our psychological health support programme developed in response to the specific needs of the medical team. The programme consists of five modules, including a daily measurement of mood (referred to as a psychometer), positive selffeedback training (in the form of a daily mood broadcast, an online means to tell staff about positive happenings),

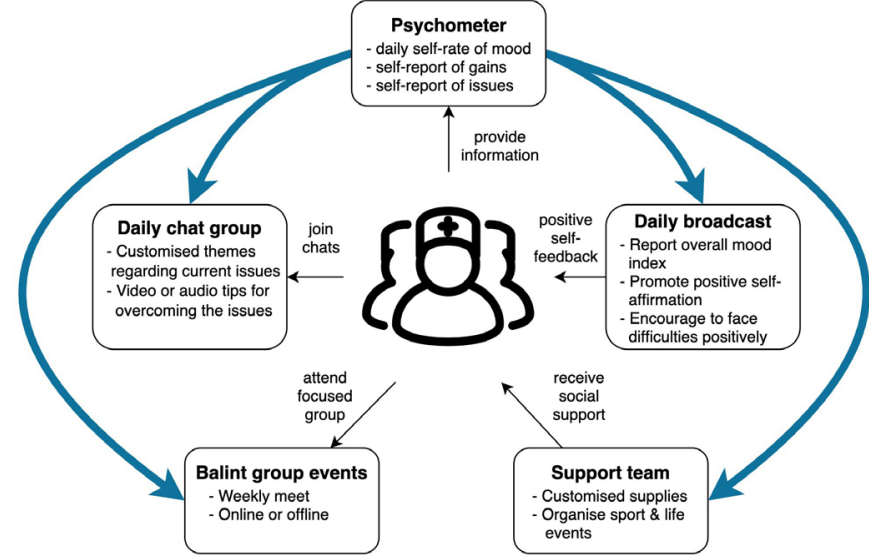

Figure 2 Psychological health support programme in Leishenshan Hospital, Wuhan, China. The programme consists of five modules, as indicated using boxes. The blue curves mark the information flow inside the programme. The black arrows indicate the interactions between modules of the programme and the medical team members.

peer-group psychological support and education (in the form of a daily online themed chat), a Balint group and an after-work support team that provides necessary life skills and organises after-work activities. As shown in figure 2, medical team members reported their emotional state, gains and issues in the psychometer module. The information then inspires the daily mood broadcasts and the topics of the daily online themed chat. The after-work support team also provides assistance to medical team members based on the needs reflected in the psychometer module (blue lines in figure 2). Medical team members receive positive self-feedback from the daily broadcast. They also obtained timely support that meets their needs, such as physical and cultural activities, from the after-work support team. At the same time, they participated in daily online themed chats and weekly Balint groups based on interests and needs during their after-work time. Details of each module are described below.

\section{Psychometer}

In the psychometer module, we created an online, anonymously completed daily mood questionnaire, which includes an age-and-gender form, a Subjective Units of Feeling (SUF) scale and a Gain-and-Issue scale. The SUF is a $0-10$ scale ( 0 for no pleasure and 10 for most intense pleasure) to measure the subjective intensity of pleasure that an individual is currently experiencing. The scale was adapted from the subjective units of distress scale (Wolf, 1969) which changes the distress rating to a positive emotional rating. The Gain-and-Issue scale consists of two semi-open-ended questions that ask for answers to the question, 'What was your biggest gain today?'; 'What is the challenge you are experiencing today?'. The results were used to capture individual impressions of gains and challenging issues. The entire questionnaire was made into a web page that could be accessed via smartphone, and a QR code link was sent to the medical team's online 
themed chat group daily. The information collected in this questionnaire was summarised daily and used as valuable reference information for other intervention modules. At the same time, these data are one of the primary sources for later data analysis.

\section{Positive self-affirmation training (in the form of a daily mood broadcast)}

Based on the level of positive emotions and positive self-reporting provided by the psychometer module, we composed a daily mood broadcast to report the mood index and convey positive feedback. We sent the daily broadcast to the medical team's online themed chat group every evening. In this way, we reinforced the selfaffirmation of the entire staff.

\section{Peer-group psychological support, and education (in the form of a} daily online themed chat)

We conducted a daily 1 hour online themed chat group to invite people to share their experiences and thoughts. The topics were selected according to the most representative issues based on the information collected daily in the psychometer module. The chat topics covered mood regulation, cognitive restructuring, problem-solving, pleasurable activities, relaxation meditation and positive mindfulness exercises (see online supplementary table 1 for specific daily chat topics). The moderator (a psychologist) also posted relevant mental health support tips in the forms of text, video and audio.

\section{Balint group}

We ran a weekly Balint group activity, namely leaded by the psychiatrist and to discuss with health care professionals. Which recruiting group members on a sign-up basis, up to 10-12 members at one time. Participants attended experiential learning from each other, tried to understand difficult emotions at work and shared solutions.

\section{After-work support team}

As an essential part of the psychological intervention programme, the after-work support team provided targeted materials based on the issues collected by the psychometer module and organised after-work activities, such as sports, cooking and photography. This team also took care of unexpected out-of-work events that occurred to the medical team members. These efforts promoted relaxation and social supports among the medical team members.

\section{Follow-up investigation}

We conducted a follow-up study of the effectiveness of our psychological health support programme after the medical team had finished their work assignment within 1 week after leaving Wuhan. An online questionnaire was sent to the entire medical team as they were in a rest-and-quarantine phase. The subjective unit of feeling questionnaires asked the following information: (1) level of attention to the daily mood broadcast $(0-10$ scale; 0: never attention, 10: special attention); (2) subjective effectiveness rating of the Balint group (0-10 scale; 0: no effect, 10: a very significant effect), and (3) the most impressive topics in the daily online themed chat.

\section{Data analyses}

The data collected in this study came partly from the follow-up study and partly from the psychometer data collected during the implementation of the psychological health support programme. For the follow-up questionnaire data, we depicted the distribution of the medical team members' attention to the daily broadcast and their effectiveness rating scores for the Balint group. We also calculated the percentage of 'impressive' topics in the daily online chat activity, that is, the number of individuals who were impressed with the daily topic divided by the sample size. Through these analyses, we preliminarily examined the subjective effects of the intervention programme on the medical team members.

The psychometer data collected during the implementation of the intervention programme included data from the Emotional SUF and the Gain-and-Issue scale. We first averaged the reports of the SUF across individuals to calculate a Daily Mood Index (DMI). Due to the intensive nature of emergency medical work, there were a few dates when these data could not be collected. In data analysis, therefore, we ignored these missing values. For the results of the Gain-and Issue open scales, we split the report into events. We averaged the number of daily reported gain events and the number of challenging events, respectively.

Further, we coded the reported gain events and issues as work-related, life-related and physiological. We calculated the daily average of gain-work, gain-life, gain-physiological, issue-work, issue-life and issue-physiological, respectively. At the same time, we also obtained the total number of patients under the responsibility of the daily medical team and the number of cases in critical condition.

To further investigate the effectiveness of the intervention programme, a stepwise regression analysis was used to examine how the DMI was affected by the total number of patients, the number of critical cases, the number of gains and the number of issues. Further, we examined how the three different aspects of gains and issues affected the DMI. Since the main thrust of the intervention programme is positive self-feedback and regulation, testing the effect of the number of reports of gains and issues on the DMI would reflect the effectiveness of the intervention programme.

\section{RESULTS}

Effects of group support and psychological education

One hundred and twenty-four members of the medical team responded to the follow-up investigation, including 41 doctors, 79 nurses and 4 administrative staff. As shown in table 1, this sample does not differ significantly from the entire medical team in terms of role composition. There was also no significant difference between the 
Table 1 Occupation and sex compositions of the sample and the entire medical team

\begin{tabular}{|c|c|c|c|c|c|}
\hline & & Population, n (\%) & Sample, n (\%) & $\chi^{2}$ & $P$ value \\
\hline \multirow[t]{2}{*}{ Sex } & Male & 49 (31.6) & $33(26.6)$ & 0.830 & 0.362 \\
\hline & Female & $106(68.4)$ & $91(73.4)$ & & \\
\hline \multirow{2}{*}{ Role } & Nurse & $90(58.1)$ & $79(63.7)$ & & \\
\hline & Administration & $6(3.9)$ & 4 (3.2) & & \\
\hline
\end{tabular}

sex ratio of the sample and the entire medical team (see table 1).

According to the survey, $99.2 \%$ of the participants followed the daily mood broadcast, $52.4 \%$ participated in daily themed chats and $27.4 \%$ participated in the Balint group. Figure 3A shows the distribution of respondents' attention to the daily mood broadcast. Respondents rated this using an evaluation scale of 1-10. The distribution shows a significant leftward bias, with a median of 8 , indicating that the daily mood broadcast received widespread attention from the medical staff. Figure 3B shows the distribution of the evaluation scores of respondents who had participated in the Balint group. Similar to figure $3 \mathrm{~A}$, the distribution also showed a significant leftward bias, with a median of 9 . Among the respondents, $91.2 \%$ rated 7 or higher. The results showed that the team members who participated in the Balint group were satisfied with the benefits. Figure 3C shows the percentage of respondents who were impressed by each daily themed chat activity. The highest impression rate was $43.1 \%$, the lowest $4.6 \%$ and the median $21.5 \%$, suggesting that daily themed chat activities have some influence on medical team members. The above data show that several essential components of our programme received the attention and made the medical team members feel positive.

\section{DMI and its impacting factors}

The number of people who filled out a daily SUF scale while working at Leishenshan Hospital ranged from 3 to 48 , depending on the days, with a median of 16 . Some data were missing (eg, 14-15, 20-22, 24-25 March) because of interruptions, such as the only psychiatrist had to deal with emergency of the patients or the medical team being busy with other things. Figure $4 \mathrm{~A}$ depicts the trend of the DMI over time and the daily sample size (right vertical axis). The DMI peaked on 8 March, which fell on International Women's Day. The lowest value appeared on 30 March. On this day, a further batch of

A

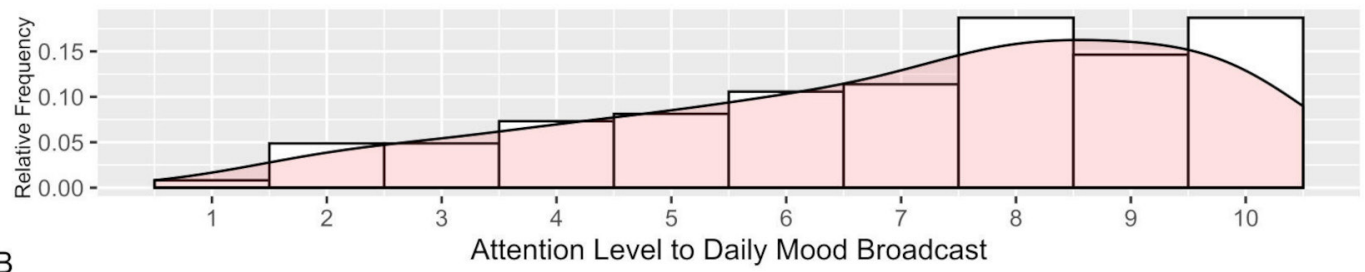

B

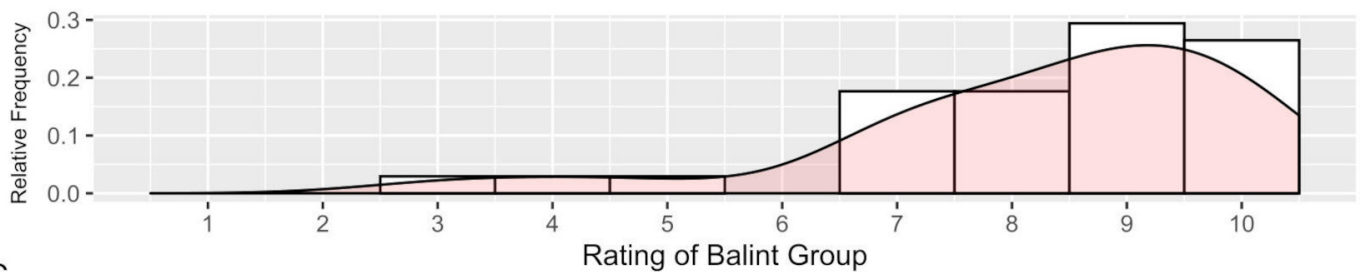

C

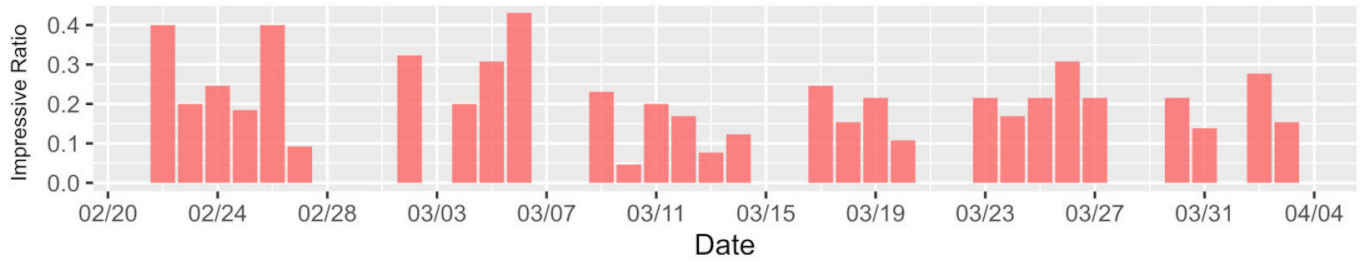

Figure 3 Results of the follow-up investigation on the effectiveness of the psychological health support programprogramme. (A) Histogram of ratings of attention level to the daily mood broadcast. The vertical axis indicates the ratio of a given level of attention among all responses; (B) Histogram of ratings of the Balint group activities. The vertical axis indicates the ratio of a given level of rating among all responses; (C) Ratios of respondents who felt 'impressive' with the daily group chat. The horizontal axis indicates the dates of the group chat activities, and the vertical axis indicates the ratio of participants who report impressiveness about the activity among all participants in a given day. 
A

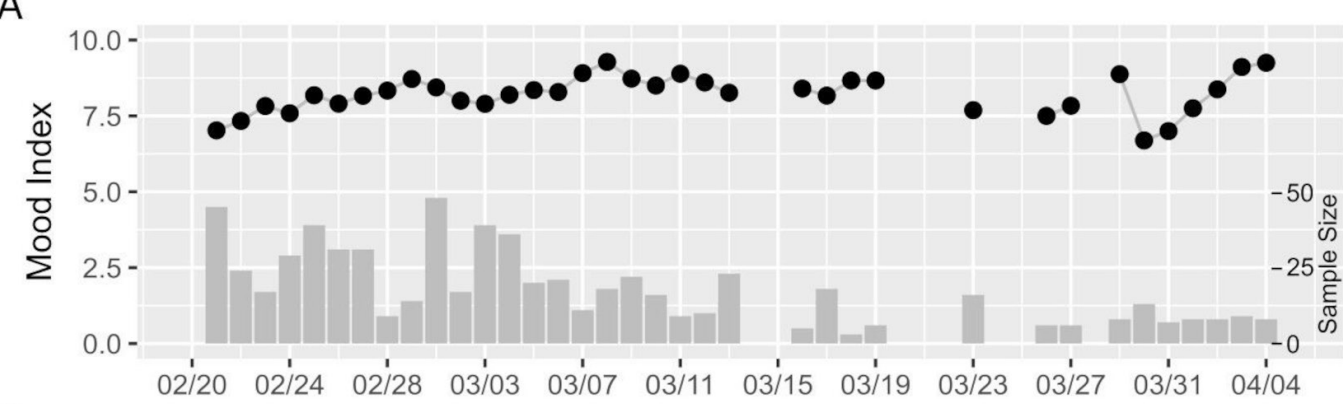

B

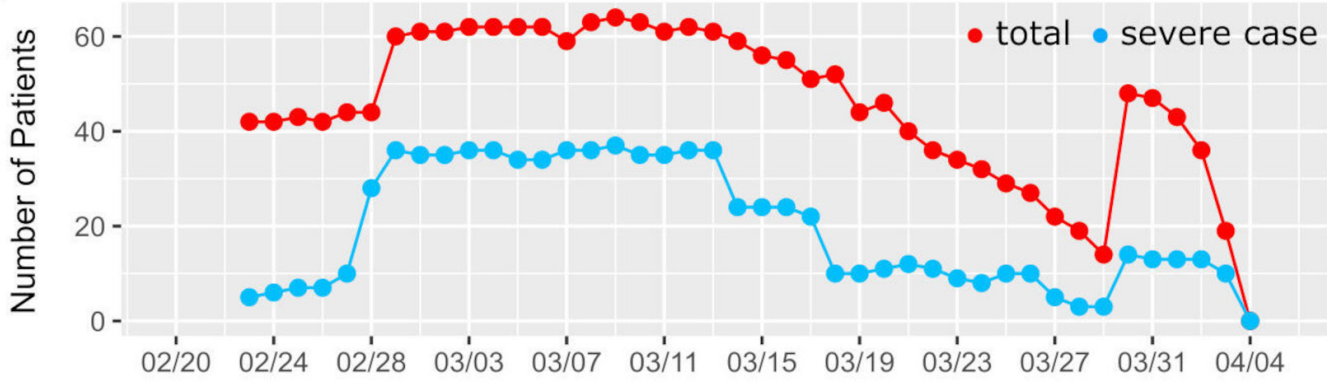

C

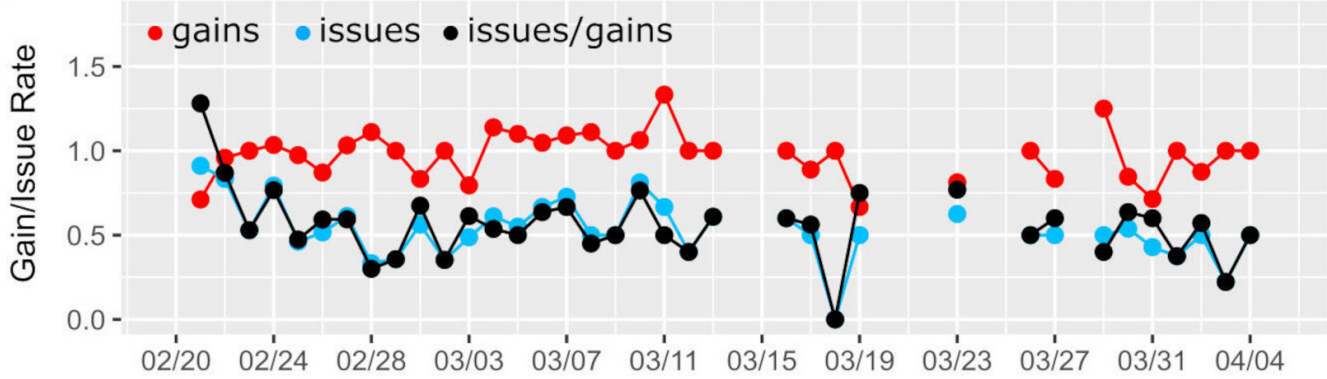

D
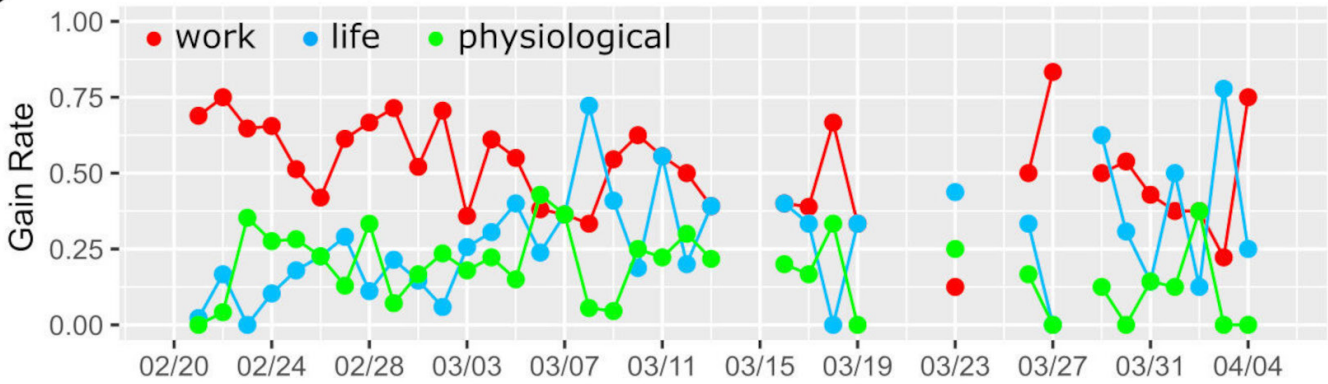

$\mathrm{E}$

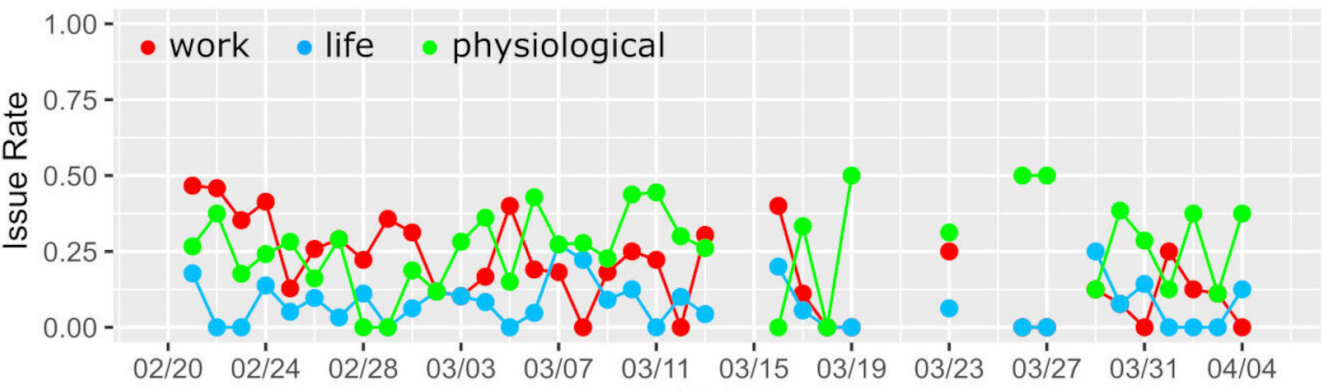

Date

Figure 4 Data collected during the real application of the psychological health support programme. (A) The Daily Mood Index (DMI) and the corresponding sample sizes. The vertical axis on the right is for the sample size. (B) Number of patients (red) and severe cases (blue) during the working period. (C) The daily average of reported gains and issues. Red: daily averaged number of reported gains; blue: daily average of reported issues; black: the fraction of reported issues by gains. (D) Three categories of the daily reported gains. Red: daily average of gains related to work; blue: daily average of gains related to life; green: daily average of gains related to physiological factors. (E) Three categories of the daily reported issues. Red: daily average of issues related to working; blue: daily average of issues related to life; green: daily average of issues related to physiological factors. 
patients, including those in critical condition, were transferred to the wards, which broke the hope of going home for the team members (figure 4B). These changes in the DMI, which are strongly associated with external events, suggest that the DMI can sensitively portray mood states of the medical team. The DMI remained high $(>8)$ most of the time compared with its initial level and the lowest point (30 March) and showed a gradual upward trend over time between 21 February and 13 March. After experiencing a valley with a sudden spike in the number of patients, the DMI quickly returned to higher levels.

Perceiving gains and building positive attitudes are essential goals of our intervention programme. As shown in figure $4 \mathrm{C}$, the average number of gains reported by medical team members increased rapidly from a starting point of 0.75 to 1.0 and subsequently above 1.0 with the implementation of the intervention programme, which means the members participating in the psychometer reported more than one gain per day on average. Conversely, the average number of issues reported fell rapidly from about 1.0 at the starting point to around 0.5 . Despite an increase between 6 March and 13 March, the ratio of issues to the number of gains remained mostly in a range of $0.25-0.75$, after 25 February. This fact suggests that the intervention programme may help to increase awareness of the gains and to promote positive attitudes.

We further classified three aspects of work, life and physiological factors according to the specific content of medical team members' reporting. Figure 4D shows the daily values of three types of gains over time. Similarly, figure $4 \mathrm{E}$ shows the daily values of three types of issues over time. The amount of reports on issues regarding work slightly decreased over time, while the amount of gains regarding life showed an upward trend.

We used stepwise regression analysis to examine how the daily average of gains/issues, the number of patients and the number of severe cases affected the DMI. We applied two linear models (table 2). Model 1 used the total number of patients, the number of severe cases, the daily average of gains and the daily average of issues as regressors to predict the variation of DMI. Model 2 further broke down the gains and issues into three types, namely the total number of patients and the number of severe cases, gain-work, gain-life, gain-physiology, issuework, issue-life, issue-physiology were used as regressors to predict the variation of DMI. The initial diagnosis of both models suggested that the data on 19 March and

Table 2 Results of regression analyses of MI

\begin{tabular}{|c|c|c|c|c|c|}
\hline \multirow[b]{2}{*}{ Model 1} & \multicolumn{5}{|c|}{ MI patients+severe cases+gains+issues } \\
\hline & $\beta$ & $\mathbf{t}$ & $95 \% \mathrm{Cl}$ & & $F$ in ANOVA \\
\hline & & & $2.5 \%$ & $97.5 \%$ & $\mathrm{df}=(1$ to 27$)$ \\
\hline Patients & -0.613 & $-2.610^{\star}$ & -1.095 & 0.131 & 0.007 \\
\hline Severe cases & 0.708 & $2.999^{\star *}$ & 0.224 & 1.192 & $16.436^{\star \star \star}$ \\
\hline Gains & 0.452 & $3.345^{\star *}$ & 0.175 & 0.728 & $9.859^{\star *}$ \\
\hline Issues & -0.233 & -0.669 & -0.520 & 0.053 & 2.786 \\
\hline Model summary & $\mathbf{R}$ & $\mathbf{R}^{2}$ & Adjusted $\mathbf{R}^{2}$ & Residual SE & $F(4$ to 27$)$ \\
\hline & 0.720 & 0.519 & 0.447 & 0.678 & $7.272^{\star \star \star}$ \\
\hline
\end{tabular}

MI patients+severe cases+gains-work+gains-life+gains-physiological+issues-work+issueslife+issues-physiological

\begin{tabular}{lllccc} 
& $\beta$ & $\mathrm{t}$ & $95 \% \mathbf{C l}$ & & $\mathrm{F}$ in ANOVA \\
\cline { 2 - 6 } Model 2 & & & $2.5 \%$ & $97.5 \%$ & $\mathrm{df}=(1$ to 24$)$ \\
Patients & -0.488 & -1.685 & -1.085 & 0.110 & 0.007 \\
Severe cases & 0.592 & $2.192^{\star}$ & 0.035 & 1.149 & $15.870^{\star \star *}$ \\
Gains-work & 0.496 & $2.573^{\star}$ & 0.098 & 0.894 & 0.049 \\
Gains-life & 0.718 & $3.277^{\star *}$ & 0.266 & 1.171 & $8.226^{\star \star}$ \\
Gains-physiological & 0.318 & 1.784 & -0.049 & 0.687 & 2.436 \\
Issues-work & -0.215 & -1.359 & -0.541 & 0.111 & 0.720 \\
Issues-life & - & - & - & - & - \\
Issues-physiological & -0.223 & -1.687 & -0.497 & 0.045 & 2.848 \\
Model summary & $\mathbf{R}$ & $\mathbf{R}^{2}$ & Adjusted $\mathbf{R}^{2}$ & Residual SE & $\mathbf{F}(\mathbf{4}$ to 27) \\
& 0.746 & 0.557 & 0.428 & 0.690 & $4.308^{\star *}$ \\
\hline
\end{tabular}

In model 2, the issues-life was removed by the stepwise regression, so its coefficient and statistics are not available.

${ }^{*} p<0.05 ;{ }^{* *} p<0.01 ;{ }^{* *} p<0.001$.

ANOVA, analysis of variance; MI, Mood Index. 
30 March affected the normality of the residuals, so they were eliminated.

In the two-way stepwise regression analysis, the fitting of model 1 was significant. The model showed that both the number of severe cases and the daily average of gains significantly explained the variation in DMI. The total number of patients and the daily average of issues did not reach significance. Model 2 also significantly explained the variance of DMI. The model showed that both the number of severe cases and the gain-life significantly explained the variation in DMI. The total number of patients, gain-work, gain-physiology, issue-work, issue-life and issue-physiology did not show significant effects.

The above results indicate that in addition to the significant impact of the number of severe cases on the DMI, the subjective gains reported by the medical team members, especially the daily average of life-related subjective gains, can also significantly explain the variation in DMI. The subjective sense of gain is precisely the aim of the psychological health support programme that we intended to achieve. Therefore, our programme may improve DMI by improving the subjective sense of gain.

\section{DISCUSSION}

\section{Main findings}

The main finding of our study was that the entire medical team maintained an overall positive outlook with a DMI mainly between 7 and 9 out of 10 for nearly 6 weeks of continuous working. The number of severe cases had a significant effect on the DMI of the medical team. Further analysis of the reported gains showed a significant effect of life-related gains on DMI. Since the primary feature of this psychological support programme was to promote self-strengths and positive self-affirmation, these findings support the effectiveness of this psychological support programme. Meanwhile, the follow-up investigations also revealed that the modules of the programme, such as positive self-affirmation training (daily broadcast), peer psychological support and education (daily themed chat) and the Balint group, received high levels of attention and evaluation from staff, supporting the effectiveness of this programme.

A highlight of our psychological health support programme is that it reconciles the mental health needs of medical team members in extreme settings with the minimal resources available for mental health support. Research has shown that exposure to a working environment where patients' conditions changed rapidly, were severe, urgent or even fatal could increase occupational exhaustion and trigger psychological trauma, thus adversely affecting the emotion and behaviour of healthcare workers. ${ }^{1920}$ Impairment of mental health and quality of life could affect the quality of medical care, increase medical errors and reduce job satisfaction. ${ }^{21}$ Furthermore, emotional burden, excessive workload and frustrations due to lack of control are potential risks for stress and burn-out. ${ }^{22}$ Additionally, being away from home, inability to connect with family and lack of family support due to work are also significant risk factors for occupational exhaustion in healthcare workers. ${ }^{21}{ }^{23}$ Given that these risk factors coincided together with medical teams in the midst of a disaster (the COVID-19 pandemic), it was necessary to apply a psychological support programme.

Indeed, as shown in this study, the DMI of medical team members was adversely impacted when the workload increased, as reflected in the number of severe cases. On the other hand, positive events especially positive life experiences could enhance the DMI of medical team members. Therefore, in the midst of major disasters, it is necessary and crucial to maintain the mental state of front-line healthcare workers to ensure their adequate working status and health, despite minimal resources for mental health support. ${ }^{24}$ The psychological support programme presented here is an effective and promising solution.

The core ideas of this programme are resource-based learning, peer support and positive self-affirmation training. The daily mood broadcasts, online themed chat groups and Balint group activities in the programme were all designed around these aims. Studies have shown that positive self-affirmation promotes healthy behaviours, better academic performance and more prosocial behaviours, ${ }^{25-27}$ as well as improving psychological and physical well-being. ${ }^{28}$ Self-affirmation acts as a defence mechanism to help mobilise the individual's internal resources and enhance psychological openness and flexibility when facing external threatening events. ${ }^{29}$ When psychologically threatened, well-functioning selfaffirmation becomes a protective factor that enhances internal resources, broadens the perspective on events and uncouples the self and threat, thus protecting selfesteem. ${ }^{25} 3031$ Research on healthcare workers has also found a significant relationship between self-efficacy and burn-out. ${ }^{32}$ Healthcare workers with better self-efficacy reported higher job satisfaction. They were more likely to mobilise new resources when faced with difficulties and obstacles, such as seeking help from colleagues and supervisors. They were also more motivated, persistent and engaged in their work. ${ }^{3-36}$ Social support is another powerful buffer against the adverse effects of emergency stressors and traumatic events, with better social support preventing and reducing the incidence and severity of post-traumatic stress disorder. ${ }^{37}$ Moreover, both self-efficacy and social support play an essential role in reducing and ameliorating the adverse effects of traumatic events. ${ }^{38}$ The above arguments explain the effectiveness of the core ideas in this psychological health programme.

Previous studies on psychological interventions for medical workers have mainly focused on long-term programmes to reduce burn-out. ${ }^{13} 3940$ While a study has reported psychological intervention efforts, such as educational lectures and face-to-face psychotherapies for medical staff treating patients infected with severe acute respiratory syndrome, ${ }^{41}$ the literature on psychological 
intervention programmes for medical staff under highrisk continuous emergency work is sparse. In recent qualitative research, Jonker et al proposed a framework for psychological trauma management in high-risk occupations that highlights three levels of interventions for acute stress. ${ }^{42}$ The primary interventions are a job-related resource, management support and immediate needs; the secondary intervention is psychoeducation and a team-based approach; and the tertiary interventions are onsite psychological support, psychological assessment and connection with social support. The five modules in our psychological health support programme fit this framework. The support team tried to satisfy the needs of staff from food to life events (primary intervention), the Balint group and daily chat group provided psychoeducation and team-based psychological social support (secondary intervention), the daily broadcast promoted positive self-affirmation (secondary intervention) and the psychometer collected data on daily mood and needs of team members (tertiary intervention). Therefore, our programme provided comprehensive coverage for the various aspects of preventing psychological issues.

\section{Limitations}

Considering the high working pressure of medical team members in Wuhan, we were worried that filling in standardised scales for evaluation of emotions and other conditions would increase their burden, which led to the lack of standardised scales for evaluation of intervention efficacy in this study. In addition this research lacks a control group to further demonstrate the effectiveness of interventions.

\section{Implications}

As the number of victims of global disasters continues to increase, the damage caused by disasters to humans will also increase. It is necessary to formulate defence strategies, related intervention teams and working mechanisms. The psychological support programme we designed in the practice of maintaining the mental health of medical staff can be used as part of the disaster prevention strategy.

\section{Author affiliations}

${ }^{1}$ Department of Psychiatry, Shanghai Mental Health Center,Shanghai General Hospital, Shanghai Jiao Tong University School of Medicine, Shanghai, China ${ }^{2}$ Department of Psychiatry, Shanghai General Hospital,Shanghai Jiao Tong University School of Medicine, Shanghai, China

${ }^{3}$ Department of Psychiatry, Shanghai Mental Health Center,Shanghai Jiao Tong University School of Medicine, Shanghai, China

${ }^{4}$ Department of Cardiology, Shanghai General Hospital, Shanghai Jiao Tong University School of Medicine, Shanghai, China

${ }^{5}$ Department of Scientific Research Administration, Shanghai General Hospital,Shanghai Jiao Tong University School of Medicine, Shanghai, China ${ }^{6}$ Department of Administration, Shanghai General Hospital, Shanghai Jiao Tong University School of Medicine, Shanghai, China

${ }^{7}$ Laboratory of Psychological Health and Imaging, Shanghai Mental Health Center,Shanghai Jiao Tong University School of Medicine, Shanghai, China ${ }^{8}$ Institute of Psychological and Behavioral Science, Shanghai Jiao Tong University, Shanghai, China

${ }^{9}$ Department of Nephrology, Shanghai General Hospital,Shanghai Jiao Tong University School of Medicine, Shanghai, China
Contributors WC: study design, data collection, data interpretation, literature search, writing. FZ: data collection, data analysis, literature search, writing. ZL: literature search, writing. $\mathrm{HZ}$ : data collection. YL: data collection. HX: data collection: JG: data collection. YH: study design, data interpretation. ZY: study design, data interpretation, data analysis, figures, writing. JL: study design, data interpretation.

Funding This work was supported by National Natural Science Foundation of China (81971682, 81571756, 81270023); Project of Shanghai Children's Health Service Capacity Construction (GDEK201702); Clinical Research Project of Shanghai Mental Health Center (CRC2019ZD04); Shanghai Municipal Commission of Education - Gaofeng Clinical Medicine Grant Support (20171929); Hundred-Talent Fund from Shanghai Municipal Commission of Health (2018BR17); Research Funds from Shanghai Mental Health Center (13dz2260500; 2018-YJ-02; ZY, 2018-YJ-03).

Competing interests None declared.

Patient consent for publication Not required.

Ethics approval The ethical committee in Shanghai General Hospital has approved this study (2020KY036).

Provenance and peer review Not commissioned; externally peer reviewed.

Data availability statement Data are available on reasonable request. Please contact the corresponding author or the first author via email.

Open access This is an open access article distributed in accordance with the Creative Commons Attribution Non Commercial (CC BY-NC 4.0) license, which permits others to distribute, remix, adapt, build upon this work non-commercially, and license their derivative works on different terms, provided the original work is properly cited, appropriate credit is given, any changes made indicated, and the use is non-commercial. See: http://creativecommons.org/licenses/by-nc/4.0/.

ORCID iD

Wenhong Cheng http://orcid.org/0000-0003-4469-9442

\section{REFERENCES}

1 Zhao Q, Hu C, Feng R, et al. Investigation of the mental health of patients with novel coronavirus pneumonia. Chin J Neurol 2020;53. in Chinese.

2 Lai J, Ma S, Wang Y, et al. Factors associated with mental health outcomes among health care workers exposed to coronavirus disease 2019. JAMA Netw Open 2020;3:e203976.

3 Zhu J, Sun L, Zhang L, et al. Prevalence and influencing factors of anxiety and depression symptoms in the first-line medical staff fighting against COVID-19 in Gansu. Front Psychiatry 2020;11:386.

4 Zhang C, Yang L, Liu S, et al. Survey of insomnia and related social psychological factors among medical staff involved in the 2019 novel coronavirus disease outbreak. Front Psychiatry 2020;11:306.

5 Chen Q, Liang M, Li Y, et al. Mental health care for medical staff in China during the COVID-19 outbreak. Lancet Psychiatry 2020;7:e15-16.

6 Kang L, Ma S, Chen M, et al. Impact on mental health and perceptions of psychological care among medical and nursing staff in Wuhan during the 2019 novel coronavirus disease outbreak: a cross-sectional study. Brain Behav Immun 2020;87:11-17.

7 Liu Z, Han B, Jiang R, et al. Mental health status of doctors and nurses during COVID-19 epidemic in China. SSRN Electronic Journal 2020.

8 Zhang A, Tao H, Ellenbecker $\mathrm{CH}$, et al. Job satisfaction in mainland China: comparing critical care nurses and general ward nurses. $J$ Adv Nurs 2013;69:1725-36.

9 Liang D, Mays VM, Hwang W-C. Integrated mental health services in China: challenges and planning for the future. Health Policy Plan 2018;33:107-22.

10 Thirthalli J, Zhou L, Kumar K, et al. Traditional, complementary, and alternative medicine approaches to mental health care and psychological wellbeing in India and China. Lancet Psychiatry 2016;3:660-72.

11 Xiang Y-T, Zhao Y-J, Liu Z-H, et al. The COVID-19 outbreak and psychiatric hospitals in China: managing challenges through mental health service reform. Int J Biol Sci 2020;16:1741-4.

12 Priebe S, Omer S, Giacco D, et al. Resource-oriented therapeutic models in psychiatry: conceptual review. $\mathrm{Br} J$ Psychiatry 2014;204:256-61.

13 Dreison KC, Luther L, Bonfils KA, et al. Job burnout in mental health providers: a meta-analysis of 35 years of intervention research. $J$ Occup Health Psychol 2018;23:18-30. 
14 Zhang J, Wu W, Zhao X, et al. Recommended psychological crisis intervention response to the 2019 novel coronavirus pneumonia outbreak in China: a model of West China Hospital. Precis Clin Med 2020;3:3-8.

15 Büssing A, Falkenberg Z, Schoppe C, et al. Work stress associated cool down reactions among nurses and hospital physicians and their relation to burnout symptoms. BMC Health Serv Res 2017;17:551.

16 Kjeldmand D, Holmström I. Balint groups as a means to increase job satisfaction and prevent burnout among general practitioners. Ann Fam Med 2008;6:138-45.

17 Aryankhesal A, Mohammadibakhsh R, Hamidi Y, et al. Interventions on reducing burnout in physicians and nurses: a systematic review. Med J Islam Repub Iran 2019;33:77.

18 Bianchi EF, Bhattacharyya MR, Meakin R. Exploring senior doctors' beliefs and attitudes regarding mental illness within the medical profession: a qualitative study. BMJ Open 2016;6:e012598.

19 Bragard I, Dupuis G, Fleet R. Quality of work life, burnout, and stress in emergency department physicians: a qualitative review. Eur $J$ Emerg Med 2015;22:227-34.

20 Crowe L. Identifying the risk of compassion fatigue, improving compassion satisfaction and building resilience in emergency medicine. Emerg Med Australas 2016;28:106-8.

21 West CP, Dyrbye LN, Shanafelt TD. Physician burnout: contributors, consequences and solutions. J Intern Med 2018;283:516-29.

22 dos Santos TM, Kozasa EH, Carmagnani IS, et al. Positive effects of a stress reduction program based on mindfulness meditation in Brazilian nursing professionals: qualitative and quantitative evaluation. Explore 2016;12:90-9.

23 Hertzberg TK, Rø KI, Vaglum PJW, et al. Work-home interface stress: an important predictor of emotional exhaustion 15 years into a medical career. Ind Health 2016;54:139-48.

24 Holmes EA, O'Connor RC, Perry VH, et al. Multidisciplinary research priorities for the COVID-19 pandemic: a call for action for mental health science. Lancet Psychiatry 2020;7:547-60.

25 Cohen GL, Sherman DK. The psychology of change: selfaffirmation and social psychological intervention. Annu Rev Psychol 2014;65:333-71.

26 Epton T, Harris PR, Kane R, et al. The impact of self-affirmation on health-behavior change: a meta-analysis. Health Psychol 2015;34:187-96.

27 Taber JM, Howell JL, Emanuel AS, et al. Associations of spontaneous self-affirmation with health care experiences and health information seeking in a national survey of US adults. Psychol Health 2016;31:292-309.

28 Emanuel AS, Howell JL, Taber JM, et al. Spontaneous self-affirmation is associated with psychological well-being: evidence from a US national adult survey sample. J Health Psychol 2018;23:95-102.
29 Correll J, Spencer SJ, Zanna MP. An affirmed self and an open mind: Self-affirmation and sensitivity to argument strength. $J$ Exp Soc Psychol 2004;40:350-6.

30 Sherman DK. Self-Affirmation: understanding the effects: SelfAffirmation: understanding the effects. Social and Personality Psychology Compass 2013;7:834-45.

31 Sherman DK, Hartson KA. Reconciling self-protection with selfimprovement: Self-affirmation theory. in: the Handbook of SelfEnhancement and self-protection. New York: Guilford Press, 2011: 128-50.

32 Amiri M, Vahedi H, Mirhoseini SR, et al. Study of the relationship between self-efficacy, general health and burnout among Iranian health workers. Osong Public Health Res Perspect 2019;10:359-67.

33 De Simone S, Planta A, Cicotto $\mathrm{G}$. The role of job satisfaction, work engagement, self-efficacy and agentic capacities on nurses' turnover intention and patient satisfaction. Appl Nurs Res 2018;39:130-40.

34 Lee TW, Ko YK. Effects of self-efficacy, affectivity and collective efficacy on nursing performance of hospital nurses. J Adv Nurs 2010;66:839-48.

35 Shahpouri S, Namdari K, Abedi A. Mediating role of work engagement in the relationship between job resources and personal resources with turnover intention among female nurses. Appl Nurs Res 2016;30:216-21.

36 Orgambídez A, Borrego Y, Vázquez-Aguado O. Self-efficacy and organizational commitment among Spanish nurses: the role of work engagement. Int Nurs Rev 2019;66:381-8.

37 Robinaugh DJ, Marques L, Traeger LN, et al. Understanding the relationship of perceived social support to post-trauma cognitions and posttraumatic stress disorder. $J$ Anxiety Disord 2011;25:1072-8.

38 Adams SW, Bowler RM, Russell K, et al. Ptsd and comorbid depression: social support and self-efficacy in world Trade center tower survivors 14-15 years after 9/11. Psychological Trauma: Theory, Research, Practice, and Policy 2019;11:156-64.

39 Le Blanc PM, Hox JJ, Schaufeli WB, et al. Take care! the evaluation of a team-based burnout intervention program for oncology care providers. J Appl Psychol 2007;92:213-27.

40 Cohen M, Gagin R. Can skill-development training alleviate burnout in hospital social workers? Soc Work Health Care 2005;40:83-97.

41 Zhang Y, Qiu Y, Kuang A, et al. Comparison of psychological status and sleep disorder between earlier stage and final stage of psychological intervention in 32 medical staff of SARS wards. Heath Psycho J 2004;12:336-7. (in Chinese).

42 Jonker BE, Graupner LI, Rossouw L. An intervention framework to facilitate psychological trauma management in high-risk occupations. Front Psychol 2020;11:530.

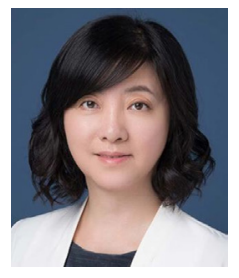

Wenhong Cheng is the chief physician of Department of Psychiatry at Shanghai General Hospital and the associate chief physician of the Department of Child and Adolescent Psychiatry at Shanghai Mental Health Center, both affiliated to Shanghai Jiao Tong University School of Medicine. She is a psychiatrist as well as a psychotherapist. She is the deputy director of the Cognitive-Behavioral Therapy group, and the Child and Adolescent Psychiatry Group of the Chinese Psychiatrist Association. She is also the director of the Child and Adolescent Psychiatry group of the Shanghai Medical Association. In addition, she is the director of the Mental Health Group of the Lei Shen Shan Hospital in Wuhan, China. Her main research interests include the psychopathological mechanisms and psychological intervention effects of childhood anxiety and mood disorders, and trauma related mental health. 